\title{
Influence of Maternal Praise on Developmental Trajectories of Early Childhood Social Competence
}

\author{
Ryoji Shinohara $^{1,2}$, Yuka Sugisawa ${ }^{1,3}$, Lian Tong ${ }^{1,3}$, Emiko Tanaka $^{1,3}$, Taeko Watanabe $^{1,3}$, \\ Yoko Onda ${ }^{1,3}$, Yuri Kawashima ${ }^{1,3}$, Maki Hirano ${ }^{1,3}$, Etsuko Tomisaki ${ }^{1,3}$, \\ Yukiko Mochizuki ${ }^{1,3}$, Kentaro Morita ${ }^{1,3}$, Gan-Yadam Amarsanaa ${ }^{1,3}$, Yuko Yato ${ }^{1,4}$, \\ Noriko Yamakawa $^{1,5}$, Tokie Anme ${ }^{1,3}$ \\ ${ }^{1}$ Research Institute of Science and Technology for Society, Japan Science and Technology Agency, Tokyo, Japan \\ ${ }^{2}$ Center for Birth Cohort Studies, Interdisciplinary Graduate School of Medicine and Engineering, \\ University of Yamanashi, Yamanashi, Japan \\ ${ }^{3}$ Graduate School of Comprehensive Human Sciences, University of Tsukuba, Ibaragi, Japan \\ ${ }^{4}$ College of Letters, Ritsumeikan University, Kyoto, Japan \\ ${ }^{5}$ Clinical Research Institute, Mie-Chuo Medical Center National Hospital Organization, Mie, Japan \\ Email: rshinohara@yamanashi.ac.jp
}

Received April 27 $7^{\text {th }}, 2012$; revised May $25^{\text {th }}, 2012$; accepted June $12^{\text {th }}, 2012$

\begin{abstract}
We aimed to clarify the effects of the praise of mothers on their 18-month-old offspring by tracing the trajectory of the latters' social competence from this time to 30 and 42 months. The participants were 226 mother-child dyads whose interaction was observed when the children were 18, 30, and 42 months old. The features of mother-child interaction, and specifically the social proficiency of the children, were examined using the Interaction Rating Scale (IRS) as an aspect of social competence. Our findings indicate that caregivers' praise of 18-month-old children is very important in promoting a high-level trajectory of child social competence from that time to 30 and 42 months. It is hoped that caregivers and health care professionals will use these findings appropriately when providing care giving support to parents.
\end{abstract}

Keywords: Child Development; Praise; Social Competence; Caregiver-Child Interaction; Longitudinal Study

\section{Introduction}

Many studies suggest that positive parenting behavior is associated with the development of social competence in children. A secure parent-child attachment, which partly flows from the sensitivity and responsiveness of the caregiver, provides children with personal resources, such as emotional security and a sense of autonomy. Subsequently, these resources empower children to explore peer relationships (Ainsworth et al., 1978; Belsky et al., 1984; Lamb et al., 1985). Children derive working models from attachment relationships to their parents, that is, they internalize an enduring blueprint or a set of expectations concerning the operation of interpersonal relationships in general (Bowlby, 1969; Sroufe \& Fleeson, 1985). In addition, parental warmth and engagement are associated with prosocial behavior among young peers (Attili, 1989; Hinde \& Tamplin, 1983). Mothers who are constructive and agreeable tend to have children who exhibit similar forms of behavior in their own interactions with others (Putallaz, 1987). Inductive disciplinary styles, in which parents emphasize reasoning, are predictive of children's use of prosocial behavior (Becker, 1964; ZahnWaxler et al., 1979).

Within positive parent-child relationships, "praise" is the one of the most important factors leading to the development early social skills. Previous studies on "praise" suggest that a parent's constructive verbal feedback is related to a child's achievement incentive in the early stage of development (Kamins \& Dweck, 1999; Kelly et al., 2000); furthermore, a high frequency of praise is related to high self-esteem in the child (Felson \& Zielinski, 1989; Kelly et al., 2000; Stipek et al., 1992). However, these reports focus on a 14-year-old child, who had been followed from 2 years of age. Few similar studies on toddlers exist in the literature.

With the increase in the antisocial behavior and aggression of school-aged children, the development of social competence in youngsters is of high interest. Health care and welfare specialists must urgently develop an evaluation method for assessing the development of social competence in children and for employing it to support childcare. However, Japan, possesses few such methods. Therefore, we developed a Japanese version of the Interaction Rating Scale (IRS), which can be easily and accurately used to assess several aspects of social competence in children. The reliability and validity of the IRS is found to be satisfactory in another study (Anme et al., 2007; Anme et al., 2010).

In a previous study, we examine the longitudinal relationship between the social competence of children at 18 months of age and the caregiver's attitude of "praise," with particular emphasis on the change in child attitudes at 4 and 9 months of age, after controlling for confounding factors. We find that the "praise" of caregivers influenced children's social competence at 18 months of age (Shinohara et al., 2009; Shinohara et al., 2010). In an effort to trace the impact of such praise over time, we go on to assess the children's social competence at 30 and 42 months and indicate the changes in their attitudes from the time when these youngsters were 4 and 9 months old. We place 
particular emphasis on the actual behaviors of caregivers extending praise, in a situation involving mothers and 18-monthold children.

We use a group-based semiparametric approach (Nagin, 1990: Nagin, 2005) to analyze the trajectory social competence development in children. This statistical technique enables us to evaluate subgroups of participants, multiple patterns of change in the outcome, and the shape of the change over time, etc. This model can be estimated using The SAS Trajectory Procedure "ProcTraj" described in Jones, Nagin, and Roeder (2001), and Jones and Nagin (2007). Further, Arrandale, Koehoorn, Mac$\mathrm{Nab}$, and Kennedy (2006) offer explanations of "ProcTraj".

The present study is longitudinal in nature and examines relationship between three variables: first, the trajectory of social competence in children from 18 months to 30 and 42 months; second, the actual behaviors of caregivers offering praise at 18 months; and finally, the change in the attitudes of children over time, beginning at 4 and 9 months. Demographic variables with the potential to influence this relationship are controlled for. The actual behaviors of caregivers offering praise to 18-monthold children are emphasized.

\section{Methods}

\section{Participants and Overview}

Data was obtained from 231 mother-child dyads enrolled in a longitudinal study of social development conducted as part of a project initiated by the Japan Science and Technology Agency (JST). The children and their parents were recruited from two Japanese cities (Mie and Osaka). Laboratory-based videotaped observations of all dyads were made three times, once when the children were 18 months old in 2007, and the others at 30 and 42 months, in 2008 and 2009 respectively. However, the analyses are restricted to the 226 dyads for which the mothers provided demographic data and completed a questionnaire on their attitudes towards the importance of praise when their children were 4 months and 9 months old. All mothers gave informed written consent before participating in the study, the protocol of which was approved by the ethics committee of the JST.

\section{Measures}

Demographic data and attitudes regarding praise were obtained from the questionnaire. Demographic variables include the gender of the child, the presence of siblings, the family type (nuclear or extended), and the age of the mother (see Table 1). The item addressing the caregiver's attitude towards the importance of praise is termed "Praising child"; it has four response options: 1) Not at all important; 2) Of minor importance; 3) Fairly important; and 4) Very important (see Table 2).

\footnotetext{
${ }^{*}$ The child-related subscales are 1) Autonomy: Child initiates interaction with caregiver; 2) Responsiveness: Child is responsive to caregiver's behavioral cues; 3) Empathy: Child behaves in accord with caregiver's affective expression; 4) Motor regulation: Child's behavior is clearly directed toward the task and he/she is not overactive/underactive; and 5) Emotional regulation: Child adjusts his/her emotional state to a comfortable level. The caregiver-related subscales are 6) Respect for the development of autonomy Partner encourages child's autonomy; 7) Respect for the development of responsiveness: Partner encourages child's responsiveness; 8) Respect for the development of empathy: Partner encourages the child to develop empathy; 9) Respect for cognitive development: Caregiver encourages child's cognitive development; and 10) Respect for social-emotional development: Caregiver encourages child's social-emotional development.
}

Table 1.

Demographic information.

\begin{tabular}{lccc}
\hline \multicolumn{1}{c}{ Variable } & Category & $\mathrm{n}$ & $\%$ \\
\hline Gender & 0 & 116 & 51.3 \\
Boy & 1 & 110 & 48.7 \\
Girl & 0 & 115 & 50.9 \\
& 1 & 88 & 38.9 \\
Numbers of siblings & 2 & 22 & 9.7 \\
& 3 & 1 & 0.5 \\
Family type & & & \\
Nuclear & 0 & 193 & 85.4 \\
Extended & 1 & 33 & 14.6 \\
Mother's age & & & \\
$20-29$ & & 57 & 25.2 \\
$30-39$ & Continuous variable & 158 & 69.9 \\
40 - 49 & & 11 & 4.9 \\
\hline
\end{tabular}

Table 2.

Caregiver's attitude towards the importance of praise.

\begin{tabular}{|c|c|c|c|c|c|}
\hline Respondent & $\begin{array}{l}\text { Child's age } \\
\text { (months) }\end{array}$ & Attitude & Category & $\mathrm{n}$ & $\%$ \\
\hline & & 1. Not at all important & & 0 & 0.0 \\
\hline & & 2. Of minor importance & 0 & 0 & 0.0 \\
\hline & & 3. Fairly important & & 10 & 4.4 \\
\hline & & 4. Very important & 1 & 216 & 95.6 \\
\hline \multicolumn{6}{|l|}{ Mother } \\
\hline & & 1. Not at all important & & 0 & 0.0 \\
\hline & \multirow{3}{*}{9} & 2. Of minor importance & 0 & 1 & 0.4 \\
\hline & & 3. Fairly important & & 12 & 5.3 \\
\hline & & 4. Very important & 1 & 213 & 94.3 \\
\hline
\end{tabular}

The IRS was used to assess social competence in children and child-rearing competence in mothers. This measure has 10 subscales, five addressing each of the child-related and caregiver-related factors ${ }^{*}$. Scores for all IRS subscales are derived from laboratory-based observations of mother-child interactions. The 36 items of the IRS are based on items of the Nursing Child Assessment Satellite Training (NCAST) teaching scales (Sumner \& Spietz, 1994); we also refer to the Home Observation for Measurement of the Environment (HOME; Caldwell \& Bradley, 1984) and the Social Skills Rating Systems (SSRS; Gresham \& Elliot, 1990).

The internal consistencies (Cronbach's alpha $=\alpha$ ) ofIRS (Sugisawa et al., 2010) were as follows. The internal consistency of the whole level of IRS was 0.91 , and the $\alpha$ values in the domains of the child and caregiver were 0.88 and 0.85 , respectively. Regarding the internal consistencies in the five subscales related to the child, the child's 1) Autonomy ( $\alpha=$ $0.74)$; 2) Responsiveness $(\alpha=0.61)$; 3) Empathy $(\alpha=0.70)$; 4$)$ Motor regulation $(\alpha=0.43)$ and (5) Emotional regulation $(\alpha=$ 
0.66). In the subscales related to thecaregivers; 6) Respect for the development of autonomy $(\alpha=0.59)$; 7) Respect for the development of responsiveness $(\alpha=0.62)$; 8) Respect for the development of empathy ( $\alpha=0.43)$; 9) Respect for cognitive development ( $\alpha=0.70$ ); and (10) Respect for social-emotional development ( $\alpha=0.45$ ). Regarding the validity of IRS (Sugisawa et al., 2010), pearson's correlation coefficient between IRS and NCATS total scores was $0.89(p<0.001)$, the coefficient of correlation between the child's total IRS and total scores NCATS was $0.70(p<0.001)$, and the coefficient of correlation between the caregiver's total IRS and total scores NCATS was $0.98(p<0.001)$.

For the actual behaviors of caregivers offering praise, we use the two following items of the subscale (7): (7)-1. Caregiver praises child's efforts at least once during the episode; (7)-2. Caregiver verbally praises child during the episode.

\section{Mother-Child Interactions}

Mother-child interactions took place in a playroom $(4 \mathrm{~m} \times 4$ $\mathrm{m}$ ) that was furnished with a small table and a child-sized chair and that contained toys (small dolls, mini cars, and plastic toys). This was a relatively natural setting, conducive both to spontaneous interaction and to a certain degree of experimental control. The play activity was standardized in being restricted to building blocks, an age-appropriate activity popular in Japan, and began when the each parent was given a box containing the blocks. Her child then took the blocks from the box, played with them, and then put them back in the box. Mothers were asked to play with their children as they would normally at home (providing instructions or help). The play activity lasted for 5 minutes. Three mother-child interactions were allowed in each task. Children who completed the task on the first attempt were not asked to perform additional tasks. Mother-child interactions were videotaped from five different angles (cameras were in each corner of the room and on the ceiling) and soundrecorded.

\section{Coding of Mother-Child Interactions}

Coders had to be sensitive to the cues of both mothers and children. In the latter, such clues were often ambiguous or confusing and quite transitory. Sensitivity was achieved via one month of training in the coding of videotaped parent-child interactions. The coders, doctoral or master's students, achieved at least $80 \%$ inter-rater agreement during training with pilot tapes. The reliability of the coding procedure was evaluated by having two coders each analyze a sample of tapes from the study $(25 \%$ of the total) and was verified if the inter-rater agreement attained $87 \%$.

\section{Data Treatment}

\section{Attitude Variables}

Responses to the "Praising child" item were converted to a binary variable, with the response option "Very important" assigned a score of 1 (positive attitude) and all other response options assigned a score of 0 (negative attitude). From these values we construct a variable representing the transition of the attitude towards praise across the period at which the child was 4 months and 9 months old (see Table 3). This variable (Attitude variables) has four categories: 0 , reflecting a negative attitude at both ages (consistently negative); 1, reflecting a change
Table 3.

Caregiver's change of attitude towards the importance of praise.

\begin{tabular}{ccccccc}
\hline \multirow{2}{*}{ Respondent } & \multicolumn{2}{c}{ Binary variable } & Attitude & $\mathrm{n}$ & $\%$ \\
\cline { 2 - 3 } & 4 months & 9 months & & & & \\
\hline \multirow{3}{*}{ vother } & 0 & 0 & 0 & 4 & 1.8 \\
& 1 & 0 & 1 & 9 & 4.0 \\
& 0 & 1 & 2 & 6 & 2.7 \\
& 1 & 1 & 3 & 207 & 91.5 \\
\hline
\end{tabular}

in attitude from positive at 4 months to negative at 9 months (inconsistently negative); 2 , reflecting a change in attitude from negative at 4 months to positive at 9 months (inconsistently positive); and 3 , reflecting a positive attitude at both ages (consistently positive).

\section{Behavior Dummy Variables}

The two items measuring praise (Behavior variables) are (7)-1 Caregiver praises child's efforts at least once during the episode (yes $=1$, no $=0$ ) and (7)-2 Caregiver verbally praises child more than once during the episode (yes $=1$ no $=0$ ). From these values we construct the dummy variables (Behavior dummy variables: X1, X2, X3), representing the occurrence of the two items (see Table 5).

\section{Children's Social Competence}

Child-related subscale items of the IRS were assigned a score of 1 if coded as "yes" and a score of 0 if coded as "no"; the summed score across all five subscales constitute the child's total score $($ maximum $=25)$. The summed score at 18,30 , and 42 months was calculated.

\section{Statistical Approach}

The Statistical Analysis System (SAS) statistical package (Ver. 9.1) was used for the analysis. In performing this task, we calculated the descriptive demographic data, the attitude variables, the behavior variables, the behavior dummy variables, and the children's social competence at three points. The trajectories of children's social competence from 18 months to 30 and then to 42 months were estimated by using a group-based semiparametric approach (Nagin, 1990; Nagin, 2005). This method focuses on describing the trajectory, or pattern, of change over time in the dependent variables, and the ProcTraj estimates a regression model for each discrete group within the population (Arrandale, Koehoorn, MacNab, \& Kennedy, 2006). The Bayesian information criteria (BIC) were used to decide on the optimum number of groups. In the ProcTraj procedure, the BIC values given in the output are negative; the best-fit model is the one with the smallest negative number (Jones, Nagin, \& Roeder, 2001; Arrandale et al., 2006). After deciding on the optimum number of groups, we estimated the relationship between the trajectories of children's social competence, the attitude variables, and the behavior dummy variables.

\section{Results}

The demographic details, the attitude variables, the behavior variables, the behavior dummy variables, and the children's 
social competence at three points of the 226 mother-child dyads who participated in this study are summarized in Tables 1-6.

A group-based semiparametric approach (Nagin, 1990: Nagin, 2005) enables us to evaluate subgroups of participants, multiple patterns of change in the outcome, and the shape of the change over time. To analyze the trajectory social competence development in children and evaluate subgroups of participants, we calculated the BIC values from one to four groups. The optimum number of groups was two (the BIC $=-1332.72$ ) (see Table 7). Therefore, for the trajectory of children's social competence, two groups (Low group vs High Group) were adopted in this study (see Figure 1). There was a general trend for each child's social competence to increase with age.

In addition, to analyze the relationship between the trajectory social competence development in children from 18 to 42 months of age and the caregiver's behavior of "praise" when

Table 4.

Distribution of behavior variables.

\begin{tabular}{cccc}
\hline Variable & Category & $\mathrm{n}$ & $\%$ \\
\hline (7)-1 Praise & 0 & 64 & 28.3 \\
no & 1 & 162 & 71.7 \\
yes & & & \\
(7)-2 Praise & 0 & 77 & 34.1 \\
no & 1 & 149 & 65.9 \\
yes & & & \\
\hline
\end{tabular}

Note: (7)-1 Praise: caregiver praises the child's efforts at least once during the episode; (7)-2 Praise: caregiver verbally praises the child during the episode.

Table 5.

Distribution of behavior dummy variables.

\begin{tabular}{ccccccc}
\hline \multicolumn{2}{c}{ Behavior variables } & \multicolumn{4}{c}{$\begin{array}{c}\text { Behavior dummy } \\
\text { variables }\end{array}$} \\
\hline $\begin{array}{c}(7)-1 \\
\text { Praise }\end{array}$ & $\begin{array}{c}(7)-2 \\
\text { Praise }\end{array}$ & $\mathrm{n}$ & $\%$ & \multicolumn{3}{c}{$\mathrm{X} 1$} \\
\hline 0 & 0 & 62 & 27.4 & 0 & 0 & 0 \\
0 & 1 & 15 & 6.6 & 1 & 0 & 0 \\
1 & 0 & 2 & 1.0 & 0 & 1 & 0 \\
1 & 1 & 147 & 65.0 & 0 & 0 & 1 \\
\hline
\end{tabular}

Note: (7)-1 Praise: caregiver praises the child's efforts at least once during the episode; (7)-2 Praise: caregiver verbally praises the child during the episode.

Table 6.

Child's social competence at three points of age.

\begin{tabular}{ccc}
\hline \multirow{2}{*}{ Age of child } & \multicolumn{2}{c}{ Child's social competence } \\
\cline { 2 - 3 } & Mean & SD \\
\hline 18 months & 21.420 & 3.545 \\
30 months & 22.452 & 2.944 \\
42 months & 22.961 & 2.565 \\
\hline
\end{tabular}

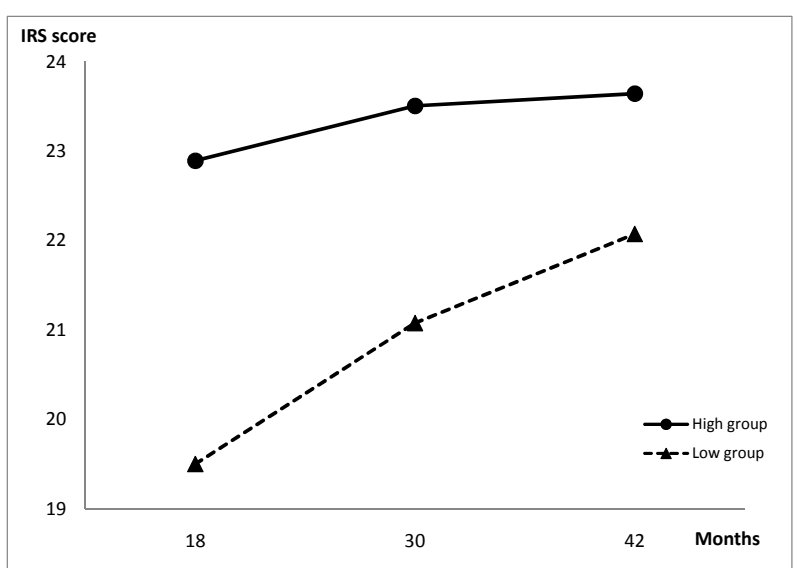

Figure 1.

Development trajectories of child's social competencefrom 18 to 42 months.

their children were 18 months of age, multinomial logistic regressions in the ProcTraj carried out.

The results show that after controlling for the effects of the demographic data, in the direction of the High group based on the Low group, the attitude variables $(\beta=1.203, p=0.036)$ and the behavior dummy variables $\mathrm{X} 3(\beta=2.619, p=0.005)$ were significantly related to the trajectory of the children's social competence (Low group vs High Group). Additionally, for the demographic data, the results reveal that the gender of the child (Girls: $\beta=1.889, p=0.026$ ), siblings (Yes: $\beta=1.024, p=$ 0.045 ) was significantly related to the trajectory of social competence (Low Group vs High Group) (see Table 8).

\section{Discussion}

\section{Characteristics of This Research}

This study is unique in the following respects. In Japan, there are few previous studies to assess the trajectory social competence development in infancy. We examined the longitudinalrelationship between the trajectory social competence development in children from 18 to 42 months of age and the parent's attitude towards the importance of praising the child when he/she was 4 or 9 months old, and the caregiver's behavior of "praise" when their children were 18 months of age.

Meanwhile, this research has limitations that hinder generalization because the participants were those who live in two cities. Moreover, the number of participants was low. However, the use of the results can be expected given that the subjects represent ordinary families in Japan.

\section{The Trajectory of Children's Social Competence and the Caregiver's Behavior of "Praise"}

The children were active and had more potential than we expected, although they could not have managed without their mothers' help and support. White (1959) explains the rich potential of competence encouragement in ensuring the healthy development of a child. Competence is defined as those "abilities [though which] the person is effectively related with the environment." In the development of a child's competence, his/her mother's response to him/her is important; that is, the 
Table 7.

The optimal number of trajectories (Liner model).

\begin{tabular}{|c|c|c|c|c|c|c|c|}
\hline Numbers of groups & Group number & $\mathrm{n}(\%)$ & Intercept & $\mathrm{p}$ value & Linear $(\beta)$ & $p$ value & BIC \\
\hline 1 & 1 & 100.0 & 20.294 & $<0.001$ & 0.097 & $<0.001$ & -1333.22 \\
\hline \multirow{3}{*}{2} & 1 & 31.0 & 16.286 & $<0.001$ & 0.146 & 0.003 & \multirow{2}{*}{-1332.72} \\
\hline & 2 & 69.0 & 22.161 & $<0.001$ & 0.071 & 0.010 & \\
\hline & 1 & 25.5 & 14.642 & $<0.001$ & 0.192 & $<0.001$ & \multirow{3}{*}{-1338.17} \\
\hline \multirow[t]{3}{*}{3} & 2 & 21.3 & 17.978 & $<0.001$ & 0.289 & 0.039 & \\
\hline & 3 & 53.2 & 23.261 & $<0.001$ & 0.004 & 0.944 & \\
\hline & 1 & 25.5 & 14.642 & $<0.001$ & 0.192 & $<0.001$ & \multirow{4}{*}{-1346.30} \\
\hline \multirow{3}{*}{4} & 2 & 21.3 & 17.978 & $<0.001$ & 0.289 & 0.039 & \\
\hline & 3 & 47.2 & 23.261 & $<0.001$ & 0.004 & 0.965 & \\
\hline & 4 & 6.0 & 23.262 & 0.178 & 0.004 & 0.994 & \\
\hline
\end{tabular}

$\mathrm{N}=$ 226; BIC: Bayesian information criterion.

Table 8.

Multinominal logistic analyses for predicting child's social competence trajectories group memberships.

\begin{tabular}{ccc}
\hline & \multicolumn{2}{c}{ Low vs High } \\
\cline { 2 - 3 } Independent variables & $\beta$ & $p$ value \\
\hline Constant & -4.659 & 0.132 \\
Gender (based on boy) & 1.889 & 0.026 \\
Numbers of siblings (based on 0 person) & 1.024 & 0.045 \\
Family type (based on nuclear family) & -0.691 & 0.502 \\
Mother's age (continuous variable) & -0.065 & 0.397 \\
Attitude variables (based on 0) & 1.203 & 0.036 \\
Behavior dummy variables (based on 0) & & \\
X1 & 2.522 & 0.123 \\
X2 & 15.503 & 0.994 \\
X3 & 2.619 & 0.005 \\
\hline
\end{tabular}

accumulation of quick and appropriate responses of the mother to her child's needs (the baby's cries, calls for help, etc.) leads to the development of the child's self-esteem. An infant's positive response to the environment affects the development of his/her social competence later on in life.

However, regarding the parent-child interaction after infancy, many studies show that the more positive the parent-child interaction, the higher the child's level of social competence later in life. Mothers with high levels of social competence and their children display more positive behaviors and emotions (LaFreniere \& Dumas, 1992), and the extent to which mothers give their children autonomy during play and teaching predicts positive assertiveness in preschoolers (Denham et al., 1990). This outcome is explained by the constructive response of mother to their children's emotions (Eisenberg et al., 1996); the latter then imitate these social and emotional behavioral patterns (Putallaz, 1987).
In a recent neuroscience study, 19 college students participated in functional magnetic resonance imaging (fMRI) experiments involving monetary and social rewards. Izuma et al. reported that the acquisition of a good reputation robustly activates reward-related brain areas, notably the striatum, and these overlap with the areas activated by monetary rewards (Izuma et al., 2008).

This research suggests that the attitudes of parents toward positive interactions with their child, particularly through the use of praise, has a very significant effect on the development of their children's social competence later in life. Such praise at 18 months influences the trajectory of social competence in children from 18 to 30 and 42 months. A follow-up study should be conducted to further clarify the mechanism underlying the effect of interactions involving praise, one that considers not just the praise-related behaviors of mothers but also those of fathers. It is hoped that caregivers and health care professionals will use these findings appropriately when providing parenting support to parents.

\section{Acknowledgements}

The research described in this report received financial support from the R\&D Area "Brain-Science \& Society" of JST/ RISTEX as part of the "Exploration of factors affecting children's cognitive and behavioral development in Japan" project. We are grateful to all of the researchers in groups cooperating on this project, and to all of the families who participated in the study. And this research was supported by the Grants-in-Aid for Scientific Research (23330174).

\section{REFERENCES}

Ainsworth, M. S., Blehar, M. C., Waters, E., \& Wall, S. (1978). Patterns of attachment: A psychological study of the Strange Situation. Hillsdale, NJ: Lawrence Erlbaum Associates.

Anme, T., Yato, Y., Shinohara, R., \&Sugisawa, Y. (2007). The reliability and validity of the assessment method for children's social competence: Parent-child interaction rating scale. Japanese Journal of Human Science of Health-Social Services, 14, 23-31

Anme, T., Shinohara, R., Sugisawa, Y., Tong, L., Tanaka, E., Watanabe, T., Onda, Y., Kawashima, Y., Hirano, M., Tomisaki, E., Mochizuki, 
Y., Morita, K., Amarsanaa, Gan-Yadam., Yato, Y., Yamakawa, N., \& Japan Children's Study Group (2010). Interaction Rating Scale (IRS) as an evidenced-based practical index of children's social skills and parenting. Journal of Epidemiology, 20, S419-S426. doi:10.2188/jea.JE20090171

Arrandale, V., Koehoorn, M., MacNab, Y., \& Kennedy, S. M. (2006). How to use SAS ${ }^{\circledR}$ ProcTraj and SAS ${ }^{\circledR}$ ProcGlimmix in respiratory epidemiology. URL (last checked 26 April 2012).

https://circle.ubc.ca/bitstream/handle/2429/834/Arrandale_guidance doc.pdf?sequence $=1$

Attili, G. (1989). Social competence versus emotional security: The link between home relationships and behavior problems at school. In B. H. Schneider, G. Attili, J. Nadel, \& R. P. Weissberg (Eds.), Social competence in developmental perspective (pp. 293-311). Dordrecht: Kluwer. doi:10.1007/978-94-009-2442-0_ 18

Becker, W. C. (1964). Consequences of different kinds of parental discipline. In M. L. Hoffman, \& L. W. Hoffman (Eds.), Review of child development research (pp. 169-208). New York: Russell Sage Foundation.

Belsky, J. (1981). Early human experience: A family perspective. Developmental Psychology, 17, 3-23. doi:10.1037/0012-1649.17.1.3

Bowlby, J. (1969). Attachment and loss, Vol. 1: Attachment (2nd ed). New York: Basic Books.

Caldwell, B. M., \& Bradley, R. H. (1984).Home observation for measurement of the environment. Little Rock, AR: University of Arkansas at Little Rock.

Denham, S. A., McKinley, M., Couchoud, E. A., \& Holt, R. (1990). Emotional and behavioral predictors of peer status in young preschoolers. Child Development, 61, 1145-1152. doi:10.2307/1130882

Eisenberg, N., Fabes, R. A., \& Murphy, B. C. (1996). Parents' reactions to children's negative emotions: Relations to children's social competence and comforting behavior. Child Development, 67, 22272247. doi:10.2307/1131620

Felson, R. B., \& Zielinski, M. A. (1989). Children's self-esteem and parental support. Journal of Marriage and the Family, 51, 727-735. doi:10.2307/352171

Gresham, F. M., \& Elliot, S. N. (1990). Social skills rating systemsecondary. Circle Pines, MN: American Guidance Service, 1-223.

Hinde, R. A., \& Tamplin, A. (1983). Relations between mother-child interaction and behavior in preschool. British Journal of Development Psychology, 1, 231-257. doi:10.1111/j.2044-835X.1983.tb00897.x

Izuma, K., Saito, D. N., \& Sadato, N. (2008). Processing of social and monetary rewards in the human striatum. Neuron, 58, 284-294. doi:10.1016/i.neuron.2008.03.020

Jones, B. L., Nagin, D. S., \& Roeder, K. (2001). A SAS procedure based on mixture models for estimating developmental trajectories. Sociological Methods and Research, 29, 374-393. doi:10.1177/0049124101029003005

Jones, B. L., \& Nagin, D. S. (2007). Advances in group-based trajectory modeling and SAS Procedure for estimating them. Sociological Methods and Research, 35, 254-571. doi:10.1177/0049124106292364

Kamins, M. L., \& Dweck, C. S. (1999). Person versus process praise and criticism: Implications for contingent self-worth and coping. Developmental Psychology, 35, 835-847.

Kelly, S. A., Brownell, C. A., \& Campbell, S. B. (2000). Mastery motivation and self-evaluative affect in toddlers: Longitudinal relations with maternal behavior. Child Development, 71, 1061-1071. doi:10.1111/1467-8624.00209

LaFreniere, P. J., \& Dumas, J. E. (1992).A transactional analysis of early childhood anxiety and social withdrawal. Development and Psychopathology, 4, 385-402. doi:10.1017/S0954579400000857

Lamb, M. E., Tompson, R., Gardner, W. P., \& Chamov, E. (1985). Infant-mother attachment. The origins and developmental significance of individual differences in Strange Situation behaviors. Hillsdale, NJ: Lawrence Erlbaum Associates.

Nagin, D. S. (1999). Analyzing developmental trajectories: A semiparametric group-based approach. Psychological Methods, 4, 139-157. doi:10.1037/1082-989X.4.2.139

Nagin, D. S. (2005). Group-based modeling of development. Cambridge, MA: Harvard University Press.

Putallaz, M. (1987). Maternal behavior and children's sociometric status. Child Development, 58, 324-340. doi:10.2307/1130510

Shinohara, R., Sugisawa, Y., Tong, L., Tanaka, E., Yato, Y., Yamakawa, N., Anme, T. and Japan Children's Study Group (2010). Factors related to social competence development of eighteen-month-old toddlers: Longitudinal perspective, with emphasis on "Praise" in the parenting of four-and-nine-month-old infants. Japanese Journal of Human Science of Health-Social Services, 16, 31-42.

Shinohara, R., Sugisawa, Y., Tong, L., Tanaka, E., Watanabe, T., Onda, Y., Kawashima, Y., Hirano, M., Tomisaki, E., Mochizuki, Y., Morita, K., Gan-Yadam, Amarsanaa., Yato, Y., Yamakawa, N., Anme, T., \& Japan Children's Study Group (2010). The trajectory of children's social competence from 18 months to 30 months of age and their mother's attitude towards the praise. Journal of Epidemiology, 20, S441-S446. doi:10.2188/jea.JE20090168

Sroufe, L. A., \& Fleeson, J. (1986). Attachment and the construction of relationships. In W. Hartup, \& Z. Rubin (Eds.), Rlationships and development (pp. 57-71). Hillsdale, NJ: Lawrence Erlbaum Associates.

Stipek, D. J., Recchia, S., \& Mcclintic, S. (1992). Study 2: 2 - 5-yearolds' reactions to success and failure and the effects of praise. Monographs of the Society for Research in Child Development, 57, 39-59.

Sugisawa, Y., Shinohara, R., Tong, L., Tanaka, E., Yato, Y., Yamakawa, N., Maeda, T., Anme, T., \& Japan Children's Study Group (2010). Reliability and validity of interaction rating scale as an index of social competence. Japanese Journal of Human Science of HealthSocial Services, 16, 43-55.

Sumner, G., \& Spieta, A. (1994). NCAST caregiver/parent-child interaction teaching manual. Seattle: NCAST Publications, University of Washington, School of Nursing, 1-168.

White, R. (1959). Motivational reconsidered: The concept of competence. Psychological Review, 66, 297-333. doi:10.1037/h0040934

Zahn-Waxler, C., Radke-Yarrow, M., \& King, R. (1979). Childrearing and children's prosocial initiations toward victims of distress. Child Development, 50, 319-330. doi:10.2307/1129406 


\section{Appendix}

\section{Japan Children's Study Group}

\section{Chairmen}

Zentaro Yamagata (Department of Health Sciences, School of Medicine, University of Yamanashi), Hideaki Koizumi (Advanced Research Laboratory, Hitachi, Ltd.)

\section{Participating Researchers}

Kevin K. F. Wong, Yoko Anji, Hiraku Ishida, Mizue Iwasaki, Aya Kutsuki, Misa Kuroki, Haruka Koike, Daisuke N. Saito, Akiko Sawada, Yuka Shiotani, Daisuke Tanaka, Shunyue Cheng, Hiroshi Toyoda, Kumiko Namba, Tamami Fukushi, Tomoyo Morita, Hisakazu Yanaka (Research Institute of Science and Technology for Society, Japan Science and Technology Agency), Yoichi Sakakihara (Department of Child Care and Education, Ochanomizu University), Kanehisa Morimoto (Graduate School of Medicine, Osaka University), Kayako Nakagawa (Graduate School of Engineering, Osaka University), Shoji Itakura (Graduate School of Letters, Kyoto University), Kiyotaka Tomiwa (Graduate School of Medicine, Kyoto University), Shunya Sogon (The Graduate Division of the Faculty of Human Relations, Kyoto Koka Women's University), ToyojiroMatsuishi (Department of Pediatrics and Child Health, Kurume University), Tamiko Ogura (Graduate School of Humanities, Kobe University), Masako Okada (Koka City Educational Research Center), Hiroko Ikeda (National Epilepsy Center
Shizuoka Institute of Epilepsy and Neurological Disorder), Norihiro Sadato (National Institute for Physiological Sciences, National Institutes of Natural Sciences), Mariko Y. Momoi, Hirosato Shiokawa, Takanori Yamagata (Department of Pediatrics, Jichi Medical University), Tadahiko Maeda, Tohru Ozaki (The Institute of Statistical Mathematics, Research Organization of Information and Systems), Tokie Anme (Graduate School of Comprehensive Human Sciences, University of Tsukuba), Takahiro Hoshino (Graduate School of Arts and Sciences, The University of Tokyo), Osamu Sakura (Interfaculty Initiative in Information Studies, The University of Tokyo), Yukuo Konishi (Department of Infants' Brain \& Cognitive Development, Tokyo Women's Medical University), Katsutoshi Kobayashi (Center for Education and Society, Tottori University), Tatsuya Koeda, Toshitaka Tamaru, Shinako Terakawa, Ayumi Seki, Ariko Takeuchi (Faculty of Regional Sciences, Tottori University), Hideo Kawaguchi (Advanced Research Laboratory, Hitachi, Ltd.), Sonoko Egami (Hokkaido University of Education), Yoshihiro Komada (Department of Pediatric and Developmental Science, Mie University Graduate School of Medicine Institute of Molecular and Experimental Medicine), Hatsumi Yamamoto, Motoki Bonno, Noriko Yamakawa (Clinical Research Institute, Mie-chuo Medical Center, National Hospital Organization), Masatoshi Kawai (Institute for Education, Mukogawa Women's University), Yuko Yato (College of Letters, Ritsumeikan University), Koichi Negayama (Graduate School of Human Sciences, Waseda University). 